\title{
Second Year Nursing Students' Experiences of Clinical Placement in a Rural Health Centre
}

\author{
Vistolina Nuuyoma ${ }^{1} \&$ Daniel Opotamutale Ashipala ${ }^{1}$ \\ ${ }^{1}$ School of Nursing, University of Namibia, Namibia \\ Correspondence: Vistolina Nuuyoma, Lecturer, School of Nursing, University of Namibia, Namibia. Email: \\ vnuuyoma@unam.na
}

Received: April 26, 2018

Accepted: June 29, 2018

Online Published: July 5, 2018

doi:10.20849/ijsn.v3i2.417

URL: https://doi.org/10.20849/ijsn.v3i2.417

\begin{abstract}
Introduction: In nursing education, it is expected that students take theoretical and practical courses. Practical components are an integral part of learning in nurses' training, which is effected through placement of students in different clinical settings. In Namibia, hospitals, clinics and health centres are popularly utilized as a clinical environment for placing nursing students at all levels of studies. However, little is known on how students experience the placement at the health centres. In 2016 Nursing students from a satellite campus were placed at a health centre.

Methods: The study followed qualitative research principles, and it was explorative, descriptive and contextual in nature. Data were collected from reflections submitted by second year nursing students from a UNAM satellite campus upon completion of their two weeks placement at a health centre in 2016. Data were analyzed using content analysis as a data analysis strategy. Trustworthiness of this study was ensured by applying the criteria of Lincoln and Guba, namely: credibility, transferability, dependability, and confirmability of the study.

Results: The five themes that emerged from the study are: 'interpersonal factors', 'students' reactions to the learning context', 'enablers of students' learning at a rural health centre', 'challenges experienced by students', and 'recommendations made by students on learning in a rural health centre'.

Conclusion: It is evident that good interpersonal interaction between nursing staff, students and patients appear to have a positive impact on learning. Students reflected on limited supply of equipment, and limited cases available as challenges experienced during their placement. Furthermore, students made suggestions to improve placements in a rural health centre.
\end{abstract}

Keywords: rural health centre, nursing students, clinical placement, clinical practice, clinical experiences, rural placement, nursing education Namibia

\section{Introduction}

The primary focus of nursing education is to produce nurses enabled to provide and support high quality care in rapidly changing healthcare settings. Nurses are health professionals who must be equipped to run, take a lead, delegate, and challenge other health care professionals in the health care environment (Hughes \& Quinn, 2013). This is because a nurse is a health professional who is at a forefront of the health care services provision. Therefore, a nursing student must be prepared to be a critical thinker and possess problem solving abilities, technological skills and specialized psychomotor skills (Gaberson \& Oermann, 2007). In nursing education, it is expected that students take theoretical and practical courses. Teaching of theoretical courses takes place at the training institution, while teaching and learning of practical components is conducted at the training institutions, specifically in simulation rooms, as well as in clinical settings outside the institution. Practical components are an integral part of learning in nurses' training and best effected through placement of students in different clinical settings. According to Bruce, Klopper, \& Mellish (2011), clinical placements allow students to apply the theory of nursing so that the integration of theoretical knowledge and practical skills in the clinical situation makes them capable of practicing the art and science of nursing.

The clinical environment or setting encompasses hospital care, day hospital care and community based care (Bruce, Kloppers \& Mellish, 2011). In Namibia, hospitals, clinics and health centres are popularly utilized as a clinical environment for the placement of nursing student at all levels of studies. A health centre is a Primary 
Health Care (PHC) facility where the following services are offered: the promotion of proper nutrition and sanitation, reproductive health including maternal health, child care and family planning, immunizations against the major infectious diseases, prevention and control of locally endemic diseases, treatment of common diseases and conditions, health education, and conducting community based services (MoHSS, 2017).

Nursing students in Namibia are expected to fulfill a number of requirements and clinical hours in disciplines as stipulated by the Health Professions Council of Namibia and in the curricula of their training programme. These disciplines are general nursing science, community health, midwifery and mental health (University of Namibia, UNAM, 2013). These clinical placement requirements also form a prerequisite to registration as a nurse/midwife with the Nursing Council of Namibia. The number of required hours is met through the allocation of students to clinical facilities, such as hospitals, health centres and clinics. In addition, students are also involved in community-based projects. Thereafter they have to submit evidence to the clinical nursing education office at the University, which then verifies and confirms that they have worked the required hours.

\subsection{Context of the Study}

The School of Nursing (SoN) was established in 2015 at the University of Namibia (UNAM) satellite campus situated in the southern part of Namibia. The school only offers an undergraduate nursing programme, and a Bachelor-Honours Degree in Nursing Science (clinical). In 2015, the school utilized the district hospital and the two clinics in town for students' clinical placements. These settings are also utilized for clinical practice by another training institution, which offers a two years nursing/midwifery programme and a three year nursing/midwifery diploma programme.

It was observed that the two clinics in town were not sufficient to meet the increasing demands of the learning needs and clinical requirements for nursing students from the two training institutions. As a result, the clinical nursing education unit at the School of Nursing at the satellite campus conducted an assessment in order to identify clinics and health centres outside town that are suitable for second year clinical placement. One the facilities identified is a health centre located $170 \mathrm{~km}$ west of town. The health centre served a catchment population of 4731 (MoHSS, 2015). The staff compliment of the health centre consisted of four (4) registered nurses/midwives, four (4) enrolled nurses, one (1) field promoter and one (1) counsellor in 2016. The health centre consists of an out-patient section, where all PHC services are offered on a daily basis. In addition, there is an 11-bed capacity in-patient section, which consists of a female ward, a male ward, a paediatric ward and a maternity ward. The health centre has six (6) outreach points, which are visited once per month and also offers school health services once per month. On average, the health centre receives 20 patients per day and the top five conditions are hypertension follow-up, diarrhoea, respiratory infections and stab wounds.

The School of Nursing at the satellite campus started placing second year nursing students at the health centre in March 2016. Due to limited accommodation in the village where the health centre is located, only three students were sent at a time and then stayed for two weeks; the campus utilizes a two weeks block delivery system. This system allocates a specified time to attend fulltime theoretical instruction at the training institution and some time for clinical practice (Bruce, Klopper \& Mellish, 2011). At the satellite campus, all nursing students spend two weeks in clinical practice and two weeks are allocated for theoretical instruction. At the end of the two weeks of placement, students are expected to submit reports that reflect on their learning experiences. Reflection is one of the categories of assessment used in the training of health professionals (Shumway \& Harden, 2003). It helps students to make strong connections between theory and practice (Correira \& Bleicher, 2008). In the Bachelor-Honours (clinical) of Nursing Science programme students are also expected to include their suggestions on how the clinical learning experiences at the health centre can be improved.

The curriculum Bachelor-Honours (clinical) of Nursing Science programme indicates an integrated rural placement programme offered at fourth year level (UNAM, 2011). During the rural placement programme, students are placed in rural health centres, clinics and hospitals in Namibia and are expected to complete procedures in General Nursing Science, Midwifery Nursing Science and Community Health Nursing Science. A study conducted in Namibia in 2001 to describe the process of the rural placement programme in nursing education and experiences of students revealed both negative and positive experiences (Iipinge \& Venter, 2003). There is no evidence of a study conducted in Namibia regarding experiences of nursing students on rural placement after the University upgraded the undergraduate nursing qualification from a diploma to honours degree level in 2009. In addition, it is the first time that second year nursing students at a satellite campus are placed in a rural health care facility; this warrants a need to conduct a study to explore their experiences. 


\subsection{Statement of the Problem}

It has been observed that nursing students have a good theoretical background but lack practical competence. Furthermore there seems to be lack of correlation between theory and practice (MoHSS, 2010). In addition, nursing students do not get enough opportunity to complete their practical procedures and exposure to required clinical procedures is insufficient because most clinical settings are congested with students. Placing second year students in a health centre was introduced a strategy to reduce the number of students in the two clinics in town and at the same time expose them to a rural setting. The health centre was adequately staffed in terms of nursing personnel, but this was the first time it was allocated students at second year level of the Bachelor-Honours (clinical) of Nursing Science programme. Little is known about how students experience the placement at the health centre. Furthermore, there is a need for the clinical nursing education unit at the satellite campus to establish whether or not there is a need for interventions to make the health centre more conducive to clinical learning. It is not known whether nursing students appreciate the clinical exposure they receive. These deliberations have led to the formulation of the research question: How do second year nursing students experience the clinical placement at a rural health centre?

\subsection{Purpose of the Study}

The purpose of the study is to explore and describe the clinical learning experiences of second year nursing students who have been allocated to a rural health centre for their rural clinical practice.

\subsection{Research Objective}

The objectives of the study are to:

a. explore the experiences of second year nursing students during clinical placement at a rural health centre.

b. identify the challenges experienced by second year nursing students during clinical placement at a rural health centre.

c. make recommendations to the clinical nursing education unit at the satellite campus on interventions that could improve learning in a clinical environment.

\subsection{Significance of the Study}

The insights from this study may be useful for quality assurance and standard of training given to nursing students at the satellite campus. It will also enlighten the School of Nursing and the Ministry of Health and Social Services on the current status of the second year level rural clinical placement programme and its implications on the nursing training. Furthermore, findings from this study will be utilized for comparisons to findings of future studies of experiences of students in their final year.

\section{Research Design and Methods}

\subsection{Research Design}

The study follows qualitative research principles, and it is explorative, descriptive and contextual in nature. According to Maree (2016), qualitative research design is naturalistic, i.e. it focuses on natural settings where interactions occur. In addition, it is also a design used to explore how people make sense of their surroundings, experiences and understanding of phenomena. It is therefore a suitable design to explore experiences of second year nursing students during placement in a rural health centre.

\subsection{Population and Sampling}

The research population consisted of the second year nursing students registered for the Bachelor of Nursing Science (clinical) honours programme at the University of Namibia satellite campus in Kharas Region, Namibia. For the academic year 2016, there were 34 second year students registered for this programme.

Purposive sampling was used to sample the research participants. The following criteria were set to purposively select study participants:

-allocated to the health centre during the period March 2016-June 2016

-submitted a reflection to the clinical nursing education unit at the satellite campus

A total of twelve students were placed at a rural health centre for clinical placement between March and June 2016. However, only ten students submitted reflections to the clinical education unit. Therefore, only ten $(n=10)$ students were included in the study: 
The table below indicates characteristics of study participants

\begin{tabular}{ll}
\hline Month of Placement & Gender \\
\hline March 2016 & 3 Males \\
April 2016 & 3 Females \\
May 2016 & 2 Females \\
June 2016 & 2 Females \\
Total participants & 10 \\
\hline
\end{tabular}

\subsection{Data Collection}

The study used textual data as a data gathering technique. This technique, collects data from written communications that explain a case under study (Maree, 2016). Data were collected from reflections submitted by nursing students upon completion of their two weeks placement at the health centre. To assist students to write reflections on clinical experiences, all nursing students at the satellite campus are introduced to the Gibbs reflective cycle. According to Gibbs (1998), the reflective learning cycle consists of six stages; description, feelings, evaluation, analysis, conclusion and action plan (see Figure. 1).

All reflections on clinical practices were written following Gibbs reflective cycle. Students who were placed at the health centre were approached and the purpose of the proposed study was explained to them. Those who agreed to their reflections being used as a data source signed consent forms. As incompleteness is one of the disadvantages of using documents as a source of study data (de Vos, Strydom, Fouche \& Delport, 2011), the researchers contacted nursing students to obtain clarity on unclear or incomplete statements where necessary.

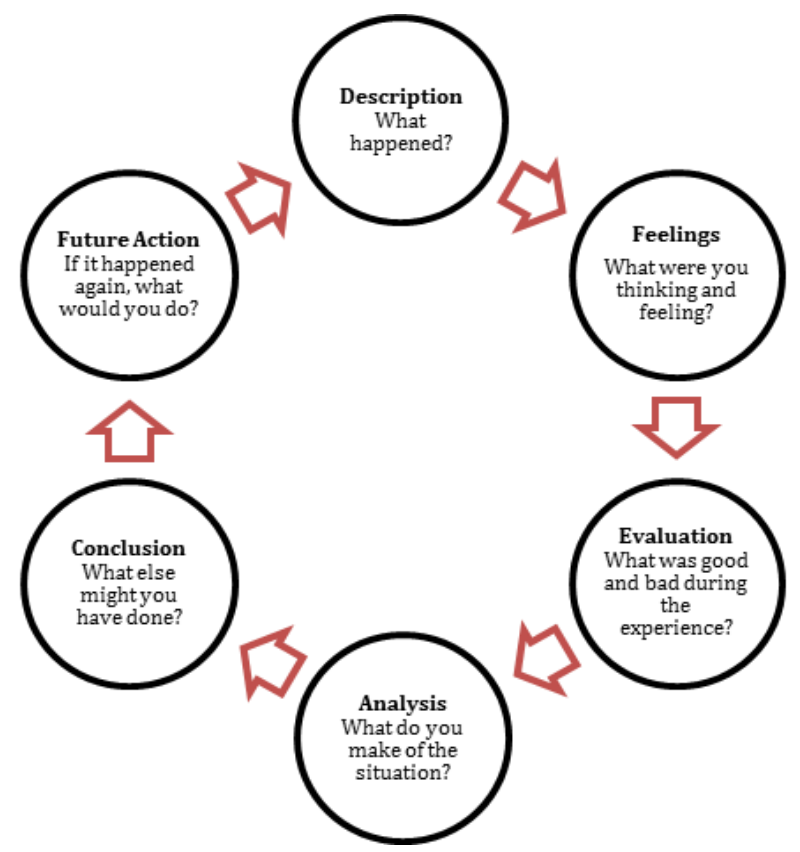

Figure 1. Gibbs reflective cycle (Adopted from Gibbs, 1998)

\subsection{Data Analysis}

The study uses content analysis as a data analysis strategy. As explained in Maree (2016), content analysis is a systemic technique of compressing many words of text into fewer categories. The researcher read through the entire reflection report of each student and made annotations in short phrases and key words in the margin. This is in accordance with de Vos, et al (2011), who indicate that short phrases and key words can be used to generate categories and code the data. Furthermore, similar texts were grouped to form themes, which constitute the findings of the study. 


\subsection{Trustworthiness}

The Trustworthiness of this study is ensured through the application of the criteria of Lincoln and Guba, namely: credibility, transferability, dependability, and confirmability of the study (Lincoln \& Guba, 1985).

To ensure credibility, the researchers made sure that students' reflection were re-read for a number of times and over an extended period of time in order to allow for prolonged engagement. The content was also summarized and shared with students for confirmation and to ensure correct interpretation.

The researchers ensured that all reports were read until no new themes were generated. As a measure to ensure dependability, the researcher provided detailed descriptions of the research settings and richly described participants and themes generated. Confirmability was ensured through a high degree of reflexivity of the researchers, who kept a personal diary to record own feelings to ensure that these did not influence the research process. Lastly, transferability was ensured by describing findings in relation to the available literature.

\subsection{Ethical Considerations}

The research study obtained ethical clearance from the Research and Publications Committee from the University of Namibia. In addition, ethical clearance was also obtained from the Ministry of Health and Social Services Research Unit. Participants signed informed consent. Anonymity was maintained by not linking data to any participant's names. The rights of the participants, such as voluntary participation and withdrawal at any time without repercussion, were emphasized in the participant information sheet.

\section{Results}

Data obtained from students' reflections on their clinical placement at the rural health centre were analysed to identify themes in order to understand the experiences. Analysis of the data relating to the experiences of second year students during clinical placement led to the emergence of five themes:

- interpersonal factors

- students' reactions to the learning context

- $\quad$ student enablers

- learning at a rural health centre

- challenges experienced by students

- recommendations made by students on learning in a rural health centre.

These themes are reflective of the learning experiences of second year students at a rural health centre as well as of challenges experienced and recommendations made.

\subsection{Theme 1: Interpersonal Factors}

This theme refers to the interpersonal factors as expressed by second year nursing students in their reflections on their learning experiences at the rural health centre. Interpersonal factors seem to serve as enablers to clinical learning. Most students express how registered nurses welcomed them and made them feel relaxed and confident in their daily clinical practice.

P 1(Note 1): The sisters at the health centre were very welcoming and made us feel at home. It never felt like we were placed for the first time at the health centre.

Furthermore, the participants reported that staff members were very helpful and displayed team spirit and a positive attitude towards the students as well as the patients. Students attribute these characteristics to the fact that the health centre belongs to the Roman Catholic Church and that Christian principles guide all workers in their daily practice.

P 6: Nurses have good interactions among each other and they work so well together with everybody at the clinic, including the patients.

$P$ 2: Staff members at the health centre pray to God together and ask for guidance before they commence daily chores. In my opinion, these help to keep order and minimize interpersonal problems.

\subsection{Theme 2: Students' Reactions to the Learning Context}

This theme elucidates participants' reactions to their placement in a rural health centre as part of their second years clinical learning experience. In their reflections, students express how they reacted to the rural health centre as a learning context. The reactions include anxiousness and embarrassment about not knowing how to carry out procedures. 
P 10: My first week was worse, I panicked and was very anxious for being around new people. I remembered the day I break the last vial of measles and all babies had gone back without immunizations. It was very embarrassing.

In some instances, participants write how they felt useless and worried about patients' wellbeing, especially when guidelines are not followed, for example:

$P$ 2: I called a registered nurse to assist me with dressing, she touched the patient's wound with unsterile glove, I felt useless, as I couldn't tell the nurse to do the right thing. In fact I was very concerned that aseptic technique guidelines were not followed.

\subsection{Theme 3: Enablers of Student Learning at the Rural Health Centre}

This theme explores students' experiences of what they identify as enablers of learning at the rural health centre as described in their reflections. Participants indicate that orientation in the geographical area of the clinic as well as learning context was provided on the first day of placement, which helped them to adapt to the new context. This is expressed as follows:

P 3: On the first day, the sister took us throughout the clinic and we saw each and every corner inside the clinic.

P 4: We were taken on a tour to different places in the settlement. This made us comfortable because we knew then what type of clients to expect at the clinic and it also gave us a better understanding of the context.

Another potential enabler revealed by the students is the availability of clear guidelines in the health centre. These are identified as a facilitator for the interaction of theory and practice while in a rural clinical setting.

P 7: One thing I like about this health centre is that there are procedure guidelines pasted on the walls. In most cases, us students don't have to carry our textbooks or summary books because these guidelines already provided steps on how to carry out a procedure.

P 6: Procedure guidelines in the clinic were very clear and they helped me integrate what I was taught in theory with what I am currently exposed to in clinical practice.

Moreover, students also recognized the feedback conveyed during their clinical placement as an enabler of learning clinical skills at the health centre.

P 3: What assisted me to learn some skills, is the corrections made by the sisters at the health centre. In general, I appreciated their feedback mechanism as it really promoted me to learn.

Most students appreciate that they were involved in patient-care related discussions and decision-making at the health centre. Students linked this to an improvement in their problem solving abilities and professional growth in general. The following are quotes from students' reflections:

$P$ 9: One day we were invited to participate in a discussion on whether the patient should be referred to a district hospital. I was feeling like this is a beginning of knowing what it really feels like to be a registered nurse, and it reminded me [that] the concept of accountability and responsibility was taught in Ethics of Nursing.

P 10: With the help of regular discussions with registered nurses, I have learnt how to solve problems, especially if you know the hospital is $170 \mathrm{~km}$ away.

\subsection{Theme 4: Challenges Experienced by Students at the Rural Health Centre}

This theme reveals the challenges experienced by the students at the rural health centre and what they describe as negative experiences during their clinical practice. Students express how they were shocked by limited supply of clinical stock and medication. These limited their ability to optimally practice procedures, but on the other hand it taught them to optimally utilize available resources. The following statement is extracted from a student's reflection:

$P$ 10: Because the clinic is located in a remote area, there are sometimes shortage of stock for medication and any other health equipment. I remember during our last week, the clinic run out of stock of measles vials and we came back without practicing how to give measles vaccination, it was very bad!

P 7: I have learn to improvise and do more with little available, I guess this is a similar situation we'll work in when we complete our training. But at the back of your head you know, there is no improvising in the examination.

Furthermore, students express how they were exposed to some health care delivery interventions and cases in the rural area. However, they feel they did not get theoretical background prior to the interventions and therefore did not learn much from the experience. 
P 5: I was selected to join the health outreach team to visit a farm a bit far from the health centre. I didn't know what to expect, since this was my first time and we didn't have any theoretical background of this model. But I was surprised to see that it was the same services that are offered at the health centre, It's only that it was in a different context.

P 3: During my first week, I had to nurse a female patient with injuries all over her body due to gender-based violence. She was physically, emotionally and sexually abused by her long-term boyfriend; they reside together. I managed to dress all her wounds, but I felt I was not prepared to nurse her emotionally. She was in emotional pain, and I felt bad because I was her first contact, but I couldn't do anything to assist her before referral for professional counselling sessions.

Due to the small population in the settlement and on farms in the vicinity of the health centre, students were not exposed to the wide variety of cases needed for clinical learning, simply because only few people came to the clinic. This is indicated as follows:

$P$ 8: Sometimes we sat at the clinic doing nothing because cases were very few. This really hindered us from learning what we expected to learn during our clinical placement.

Students also expressed how language hinders them from learning in a rural health centre. This is captured in one student's reflection as follows:

$P$ 2: One day I was working in the immunization room, one mother came there with her six weeks old baby for her second immunization after birth. I really wanted to give proper health information to this young mother, but I couldn't because she only speaks Afrikaans. I can see from her face that she had some questions but she can't communicate to me. I called a senior nurse to talk to her, and I felt so bad I was not part of the conversation. I wanted to learn so much from interaction with this young mother.

\subsection{Theme 5: Recommendations Made by Students on Learning in a Rural Health Centre}

This theme captures opinions and suggestions students made in their reflections on learning in a clinical rural health centre. As much as it is important to learn in rural areas, students feel they should at least be provided with meals. This is expressed as follows:

P 1: We really appreciated the effort made by the university, but at least in future students should be provided with food, even if it's just one meal per day.

A recommendation made by most students is to learn a third language (besides English and the mother tongue), which is spoken and understood by a majority of the Namibian population. The following quotes express this concern:

P 4: I wish I could speak Afrikaans, I really suffered a lot because most patients can't speak English or my home language. Every time I use to look for a translator, I encourage fellow students to start learning other languages

P 9: In most cases, patients preferred to be assisted by students who speak Afrikaans, this limited me from practicing my procedures because I can't communicate to my patient. So I recommend that the university introduce an informal basic language course for students to learn common local languages.

Another recommendation is directed at the students themselves. Those who worked at the health centre felt that students need to allow themselves enough time to learn and not carry out procedures in a hurry. The students further express that this will help them build confidence in the long run:

P 2: One day, I had to do an episiotomy suturing after a "primi gravida" woman delivered at the health centre. I sutured under supervision of a registered midwife but I realized that I didn't do it so well because I was too much in a rush and therefore lacked confidence in the process. My advice is that if you want to learn something, always take your time and this will help you build more confidence.

\section{Discussions}

Clinical placement of nursing students in a rural settings is a necessity as a large part of the Namibian population lives in a rural setting.. This study highlights experiences of nursing students in a rural health centre. Despite many positive interpersonal factors, students' positive reactions and enablers of learning experienced by students, key findings reveal some challenges and a need for improvement of the clinical placement in a rural setting. This discussion is organized according to the five themes that emerged as results of this study.

According to the students participating in this study, nursing staff at the rural health centre setting have good interpersonal skills; they were welcoming, and helpful towards students and work well as a team. That means that they are perceived as supportive. According to Hamshire, et al. (2017), the presence of a supportive mentor 
is necessary for guidance of learning in clinical settings. In addition, a welcoming attitude is one of the factors known to influence learning in clinical environment (Levett-Jones, et al., 2008). Good interpersonal skills of students, patients, mentors and other members of health care team are associated with promotion of learning in clinical settings (Bruce et al., 2011).

Health profession education programmes, including nursing, are considered to be challenging and time-intensive, and as a result, some students may be emotionally and academically stressed (Banks, et al., 2012). In this study, students indicate how placement in a rural setting made them anxious, and embarrassed when they did not know something, how it made them feel useless and worried. There is an indication that students are emotionally stressed.

On factors identified as enablers of learning in a rural setting, students reflect on how orientation helped in their clinical practice. A similar finding is reported by Webster et al. (2010), who indicate that clinical practice experience is enjoyable due to information on and exploration of the community associated with their placement. This is contrary to findings of Gum (2007), who reveals that orientation in rural settings was minimal.

Another enabler of learning identified in this study is feedback. Students in this study indicate that they receive regular feedback while placed at a rural health centre. Feedback is known to help students to make meaning from experiences gained in clinical settings (Watling, 2014). Furthermore, this study reveals that students were involved in patient care and decision makings at the health centre. Ipinge and Venter (2003) share similar results in their study, where nursing students placed in a rural community report that they were accepted as members of the health facility and were engaged in the discussion of health problems.

Although primary care facilities are known to be appropriate settings for clinical placement (Mc Innes, et al., 2015), students in this study expressed their dissatisfaction with clinical practice in the rural health centre. They indicate that they experienced limited supply of equipment needed to learn clinical skills. Similar results were reported by Rikhotso, Williams and de Wet (2014); students also indicate that rural settings are not conducive to learning. This is due to old-fashioned and insufficient as well as malfunctioning medical and nursing equipment, as well as a shortage of staff to guide and support them during their learning. In addition, only few clients came for service at the health centre, which means that exposure to different cases was limited. Contrary findings were reported by Webster, et al, (2010), who indicate that students had exposure to a wide variety of clients, which assisted to narrow the theory-practice gap.

Students participating in this study also indicate that they had no theoretical background of all health care service provision interventions and models used at the centre. This is similar to findings of Mc Innes, et al. (2015), which reveal that students have a limited understanding of primary health care settings. Furthermore, nursing students reflect on how lack of equipment and limited supply of clinical stock hindered their learning in a rural setting. In a previous study, Webster, et al. (2010) show that limited infrastructural, human and technological resources are identified as hindrance to learning in a rural setting. Students in this study indicated how language barriers hinder their learning at a rural health centre. This is because they are not able to communicate to clients because they speak different languages and patients are not able to communicate in the official language, English.

Language differences are a result of cultural diversity, which is one of the characteristics of the Namibian population. However, cultural diversity, including languages, are also factors that hinder nursing students from getting required guidance and support in a rural setting (Rikhotso, Williams \& de Wet, 2014).

\section{Conclusion}

The study described second year nursing students' experiences of clinical learning in a rural health centre. It is evident that good interpersonal interactions of nursing staff, students and patients appear to have a positive impact on learning. Other factors that promote learning are orientation in the health centre environment and surroundings, availability of clear guidelines, feedback given to students and involvement of nursing students in patient care and decision-making. Students reflect on the limited supply of equipment and the limited number of cases as challenges experienced during their placement. Furthermore, students made suggestions to improve placements in a rural health centre.

\section{Recommendations}

The findings of and conclusions from this study may have implications related to student placements in rural settings and for further research. The health centre's management should ensure that all equipment and clinical supplies needed for procedures to be carried out are available; this will not only benefit patients, but also students in their clinical practice. University lecturers should also ensure that nursing students have adequate 
theoretical background and are introduced to all procedures and care delivery models at the health centre. In order to facilitate communication, it is also recommended that other nursing staff help to translate when students experience language barriers. Lastly, there is a need to study the experiences of more senior students, as participants of this study were only in their second year and experiences may differ to those of more advanced students.

\section{Acknowledgement}

We thank the 2016 nursing students who participated in this study.

\section{Conflict of Interest Disclosure}

None declared

\section{References}

Banks, P., Kane, H., Rae, C., \& Atkinson, J. (2012). Support for nursing and midwifery students: a special case? Nurse Educ. Today, 32(3), 309-314. https://doi.org/10.1016/j.nedt.2011.02.010

Bruce, J., Klopper, H.C., \& Mellish, J.M. (2011). Teaching and Learning the Practice of Nursing. Cape Town: Heinemann.

Correia, M.G., \& Bleicher, R.E. (2008). Making connections to teach reflection. Michigan Journal of Community Service Learning, Spring, 41-49.

De Vos, A.S., Strydom, H., Fouche, C.B., \& Delpor, C.S.L. (2011). Research at grass roots. Pretoria: Van Schaik.

Gibbs, G. (1998). Learning by Doing: A Guide to Teaching and Learning Methods. Oxford: Oxford Further Education Unit.

Gum, L.F. (2007). Studying nursing in a rural setting: are students adequately supported and prepared for rural practice? A pilot study. Rural and Remote Health, 7, 1-17. Retrieved from http://www.rrh.org.au

Hamshire, C., Barrett, N., Langan, M., Harris, E., \& Wibberley, C. (2017). Students' perceptions of their learning experiences: A repeat regional survey of healthcare students. Nurse Education Today, 49, 168-173. https://doi.org/10.1016/j.nedt.2016.11.019

Hughes, S.J., \& Quinn, F.M. (2013). Quinn's principles and practices of nurse education. Nelson Thornes: Cheltenham.

lipinge, S.N., \& Venter, E.S. (2003, December). Nursing students' experiences during a rural community placement programme in Namibia-2001. Curationis, 5-13.

Levett-Jones, T., Lathlean, J., Higgins, I., \& McMillan, M. (2008). The duration of clinical placements: a key influence on nursing students' experience of belongingness. Aust. J. Adv. Nurs., 26, 8-16.

Lincoln, Y.S., \& Guba, E.G. (1985). Naturalistic Inquiry. London: SAGE publications.

Maree, K. (2016). First steps in research. Pretoria: Van Schaik.

McInnes, S., Peters, K., Hardy, J., \& Halcomb, E. (2015). Primary care clinical placements: The views of Australian registered nurse mentors and pre-registration nursing students (part 2). Nurse Education in Practice, 15, 443-449. http://dx.doi.org/10.1016/j.nepr.2015.04.004

Ministry of Health and Social Service (MoHSS). (2015). Keetmanshoop District Population 2015. Keetmanshoop: MoHSS.

Ministry of Health and Social. (MoHSS). (2017). Primary Health Care Services. Retrieved from http://www.mhss.gov.na/national-directorates/Primary-Health-Care-Services/49/

Ministry of Health Social Services (MoHSS). (2010). Report on Nurses consultative meeting. Windhoek: MoHSS.

Rikhotso, S.R., Williams, M.J.S., \& de Wet, G. (2014). Student nurses' perceptions of guidance and support in rural hospitals. Curationis, 37(1), 1-6. http://dx.doi.org/10.4102/curationis.v37i1.1164

Shumway, J.M., \& Harden, R.M. (2003). AMEE guide no. 25: The assessment of learning outcomes for the competent and reflective physician. Medical Teacher, 25(6), 569-584.

Watling, C.J. (2014). Unfulfilled promise, untapped potential: Feedback at the crossroads. Medical Teacher, 36, 692-697. https://doi.org/10.3109/0142159X.2014.889812 
Webster, S., Lopez, V., Allnut, J., Claque, L., Jones, D., \& Bennett, P. (2010). Undergraduate nursing students' experiences in a rural clinical placement. Aust. J. Rural Health, 18, 194-198. https://doi.org/10.1111/j.1440-1584.2010.01153.x

\section{Note}

Note 1. Study participant's number

\section{Copyrights}

Copyright for this article is retained by the author(s), with first publication rights granted to the journal.

This is an open-access article distributed under the terms and conditions of the Creative Commons Attribution license (http://creativecommons.org/licenses/by/4.0/). 